\title{
RODA VIVA NA ACADEMIA OU DA NEGAÇÃO DO PESQUISADOR CRIADOR E CRIATIVO
}

\author{
Tem dias que a gente se sente \\ Como quem partiu ou morreu \\ A gente estancou de repente \\ Ou foi o mundo então que cresceu... \\ A gente quer ter voz ativa \\ No nosso destino mandar \\ Mas eis que chega a roda viva \\ E carrega o destino prá lá ... \\ Roda mundo, roda gigante \\ Roda moinho, roda pião \\ O tempo rodou num instante \\ Nas voltas do meu coração... \\ A gente vai contra a corrente \\ Até não poder resistir \\ Na volta do barco é que sente \\ O quanto deixou de cumprir \\ Faz tempo que a gente cultiva \\ A mais linda roseira que há \\ Mas eis que chega a roda viva \\ E carrega a roseira prá lá...
}

Chico Buarque (1968)

No presente número, assim como tem se dado nos demais, o leitor encontrará as objetivações de um longo e árduo processo de criação. Certamente que a demanda de criar nem sempre coincide com a capacidade de se fazêlo, já pontuava o psicólogo e humanista L. S. Vygotski, e os autores o fazem nos limites das condições reais, que lhes geram a demanda, os recursos, as inspirações e, também, os limites. Nele estão contidos, entre outras elaborações relevantes, textos que compõem o "Dossiê da Psicologia Histórico-Cultural", que reúne análises de objetos diversos a luz de uma teoria em comum.

Neste editorial chamamos a atenção para esse universo ao qual nos prendemos, o da produção intelectual, e apresentamos nossas reflexões sobre a lógica instituída que nos tem formado, nos tem movido, mas que pode nos deformar. Para tanto, optamos por estabelecer relações ou aproximações com uma produção artística musical.

A opção por esse caminho se ancora na compreensão de que o psiquismo humano conta com as mediações sócio-históricas para se constituir e se desenvolver, e de que quanto mais ricas estas forem mais favorecem aos indivíduos a apropriação de conteúdos que podem promover seus desenvolvimentos. Esse entendimento tem nos encaminhado ao garimpo de boas obras - aquelas que apresentam uma análise mais complexa sobre um dado objeto, e que nos leva a transcendê-lo remetendo-nos a novas elaborações. Por esse simples crivo pomos em destaque uma produção na qual forma e conteúdo convergem e cumprem com o critério indicado: Roda Viva.

Sem considerarmos, nesta oportunidade, as características estilísticas, entre outros aspectos dessa obra, lembramos que houve tempos em que o sucesso radiofônico e nos festivais de música implicava em se ter uma mensagem significativa a comunicar e que pudesse, de alguma forma, impactar os seus ouvintes. $\mathrm{O}$ sucesso deveria aliar a letra criativa a uma melodia que também fosse interessante, movendo corpos e mentes, levando os ouvintes a pensarem a vida ou a si mesmos com base na realidade posta ou em um devenir comungado. Foram tempos em que se podia pensar em outra sociedade, além da vigente. 
Hoje, nem tão distantes assim, nos vemos às voltas com músicas que se emplacam como campeãs em vendas ou em solicitações que, nem de longe, se caracterizam pela capacidade de nos remeter ao real pensado, como evocavam vários sucessos das décadas de 1960 e 1970. Longe de optarmos por um saudosismo romântico, consideramos que tais elaborações pretendiam-se instrumentos para algo mais, indo além da descrição de um sujeito que se faz por si mesmo e que busca o seu bel prazer, sem a mínima vocação para sugerir quanto o sujeito se faz pelas relações sociais e que essas merecem ser alvo de interesse.

Podemos pensar que havia muito pelo que se lutar, em especial, contra a ditadura militar. Canções e peças como esta de Chico Buarque, e tantas outras de diferentes compositores reconhecidamente criativos, posto que sensíveis com o que se passava à volta, buscavam chamar a atenção e denunciar uma situação dramática em que se encontrava o Brasil, ante a defesa acirrada do capitalismo em sua expansão, que se travestia em luta contra o comunismo e os comunistas. Tinha-se, naqueles anos, a inteligência e a truculência do exército contra a inteligência e o poder de denuncia e das proposições da academia e de parte da classe artística. Os papéis foram cumpridos e os resultados são sabidos ou foram cruelmente sentidos.

Voltando-nos ao campo acadêmico, o momento atual é muito diferente daquelas décadas emblemáticas e ao mesmo tempo tão parecido. Diferente porque a luta que poderia unir os professores pesquisadores não se afirma contra um opressor torturador materializado externamente, com nome ou codinome e patente definidos, mas se apresenta dentro de cada um que precisa "bater suas metas", perseguir o inimigo que possa distraí-lo de seu produtivismo, como é o caso das preocupações com os rumos que a sociedade assume e as marcas que imprime nos indivíduos. Mas é parecido porque a lógica pela acumulação permanece e, além disso, se brutaliza em índices e metas cada vez mais inalcançáveis e se refina em seus desdobramentos metamorfoseando-se como curso natural da vida moderna e civilizada.

Nesse sentido de permanência da mesma lógica, que se altera pelo grau e extensão de seu alcance, podemos dizer que, sobretudo no âmbito da pós-graduação, a esteira está rodando em ritmo cada vez mais acelerado. Isso se dá de tal modo que em vez de fortalecer nervos e músculos, acaba por subtrair o espírito do trabalhador intelectual que em meio a produção de artigos, orientação de dissertações e teses, é requisitado para que gere conhecimento e que forme novos pesquisadores em tempos cada vez mais exíguos. Essa prática tem se constituído em nossa roda viva, que tem carregado a roseira prá lá e, por isso, merece a atenção da Psicologia que se pretende crítica, visto que comprometida em desvendar o que não se apresenta à primeira vista, as contradições entre essência e aparência.

Estamos falando sobre algo que vem sendo exposto nas associações nacionais de pós-graduação, como é o caso da Associação Nacional de Pós-Graduação em Psicologia (ANPEPP), mas que precisa ainda ser analisado, discutido e enfrentado. Essa temática, que vem sendo abordada sob diferentes análises e orientações teóricas, leva-nos a resgatar o que Vygotski já expunha nas décadas de 1920 e 1930: o ser humano é, necessariamente, criador e criativo (Vigoskii, 1998).

Essas qualidades, formadas histórica e socialmente, são inerentes ao gênero humano. Contudo, há que lembrarmos que essas formações podem ser negadas aos indivíduos, pelas condições objetivas da vida. Dizia o autor que há impulsos criadores que se voltam a reproduzir o já criado, sendo importantes por manterem a vida num patamar já conquistado. Porém, há, também, aqueles que provocam novas elaborações que, de fato, cristalizam a imaginação ou os processos criadores em algo novo. Para que elaborações dessa ordem se dêem, é necessário que nos apropriemos dos conteúdos já criados, visto se constituírem em matéria prima para se formar algo novo.

Embora muito se espere dos impulsos criativos sob essa segunda ordem no campo da Arte, em nosso caso a música, eles são fundamentais para a Filosofia e a Ciência quando estas buscam responder ao real, aos desafios e necessidades postos pelo e aos homens.

É justamente num momento em que a vocação para a humanização deveria se realizar para todos, posto que o gênero humano se apresenta num patamar de desenvolvimento tão elevado, quando a realidade se revela sob uma complexidade inimaginável ante as elaborações incessantes de novas necessidades e de produtos para satisfazêlas, que os pesquisadores são submetidos à aceleração da esteira. É num momento em que se requer tempo para desvendar e explicar o real e as múltiplas facetas que ele assume, e o modo como impacta o psiquismo, quando se impõe uma velocidade para apresentação das análises, sínteses e generalizações.

Esse processo de aceleração na produção intelectual, compreensível a luz da lógica da mercadoria, leva à formação de um quadro em que o professor pesquisador pode se apresentar cada vez mais esvaziado em um mundo de coisas que se multiplicam, de tal modo que ele mesmo se coisifica. O pesquisador, sujeito pensador e 
criador de análises e de teorias explicativas sobre o mundo e o homem, se vê na condição de ser subjugado pelo ditame das criações, que tendem, cada vez mais, a se pautarem nos impulsos reprodutivistas e não nos da segunda ordem.

Pelo modo como estamos nos pautando, direcionados pelos critérios estabelecidos para alcance de fomentos, não temos tido o tempo necessário para a apropriação, decantação e para a cristalização dos processos criativos em produtos de qualidade. Parafraseando o compositor, rosa, roseira, cultivador e apreciador - todos estão sendo levados pelo vento.

Dito de outro modo, com o aceleramento da esteira estimula-se professores pesquisadores, em especial no campo das ciências humanas, a analisarem o real, o concreto de modo a ficarem na esfera da pseudoconcreticidade. Karel Kosik (1976) argumenta que esse risco se apresenta ao se analisar a realidade tomando-a em sua aparência, pelos fenômenos da cotidianidade, da atmosfera comum da vida humana, que ante a sua constância, imediaticidade e evidência, agem sobre a consciência dos indivíduos assumindo um aspecto natural. Um exemplo de como ficar nesse nível de apropriação do real está em tomarmos o ritmo de produção imposto e o saldo que gera como naturais e inquestionáveis.

A luz da história, sabemos que do conquistado a humanidade não abre mão, mas também consideramos que estranhar e explicitar a resistência a um dado fato também constitui-se em processo de luta pela vida. Superar essa situação requer, dentre outros pontos, que se faça a crítica da práxis da humanidade, o que nos permite vislumbrar o devenir humano do homem, que se tenha uma apreensão mais abrangente e articulada dos fatos que se nos apresentam como naturais, como é o caso do aceleramento da roda ou da esteira que desemboca no produtivismo.

É preciso que cada indivíduo, no caso, o professor pesquisador, pessoalmente e sem que ninguém possa substituí-lo, forme-se e viva a sua vida como gênero particular criador e criativo, sob pena de não mais conseguir explicar o real, o homem que o cria e que por ele se humaniza.

Sonia Mari Shima Barroco Editora Assistente

\section{REFERENCIAS}

Hollanda, C., B. (1968). Roda-viva. In Álbum Chico Buarque de Holland (Vol.3). Rio de Janeiro: RGE. Música apresentada no III Festival de Música Popular Brasileira, promovido pela TV Record, em 1967.

Vigoskii, L., S. (1998). La imaginación y el arte en la infancia. (4a ed.). Madrid: Akal.

Kosik, K. (1976). Dialética do concreto. Trad. Célia Neves e Alderico Toríbio (7a ed.). São Paulo: Paz e Terra. 